\title{
A NEW RECORD OF OXYAGRION (ZYGOPTERA) FROM NORTH AMERICA
}

\author{
By Kenneth A. Christiansen \\ Boston, Mass.
}

While examining a tray of unidentified damsel flies at the Harvard Museum of Comparative Zoology, I discovered a small male cœnagrionid of unusual coloration labelled "June 9, Beltsville, Maryland." The specimen had been collected by Mr. Nathan Banks on one of two trips in 1915 and 1916. I identified the insect as Oxyagrion peterseni Ris, and this identification was later confirmed by Dr. P. P. Calvert. On further inquiry Mr. Banks informed me that the damsel fly was captured in an open Sphagnum bog which had formed over a substratum of rock. To my knowledge the only other North American record of this tropical genus is the capture of Oxyagrion rufulum in northern California. ${ }^{1}$ Needham apparently did not think that this record was sufficient reason for including the genus $O x y$ agrion in his "Handbook of the Dragonflies of North America."

I have compared the Maryland specimen of O. peterseni with the two paratypes in the collection of the Harvard Museum with the following results: The Maryland specimen is darker than the paratypes on the thoracic dorsum, and the femora of the former are lined with black whereas the legs of the paratypes are entirely yellow. ${ }^{2}$ There are eight matched post-nodal crossveins in the wings of the Maryland specimen and nine in the wings of the paratypes. In all other external features the specimens appear to be identical.

I have as yet no plausible explanation for this northern occurrence of the tropical genus; and further records are necessary to determine whether or not Oxyagrion is a true member of the North American odonate fauna.

\footnotetext{
${ }^{1}$ Muttkowski's Catalogue of the Odonata of North America, Bull. Wisc. Nat. Hist. Soc. No. 8, p. 53.

${ }^{2}$ These variations are probably due to age as the paratypes appear to be younger than the Maryland specimen.
} 

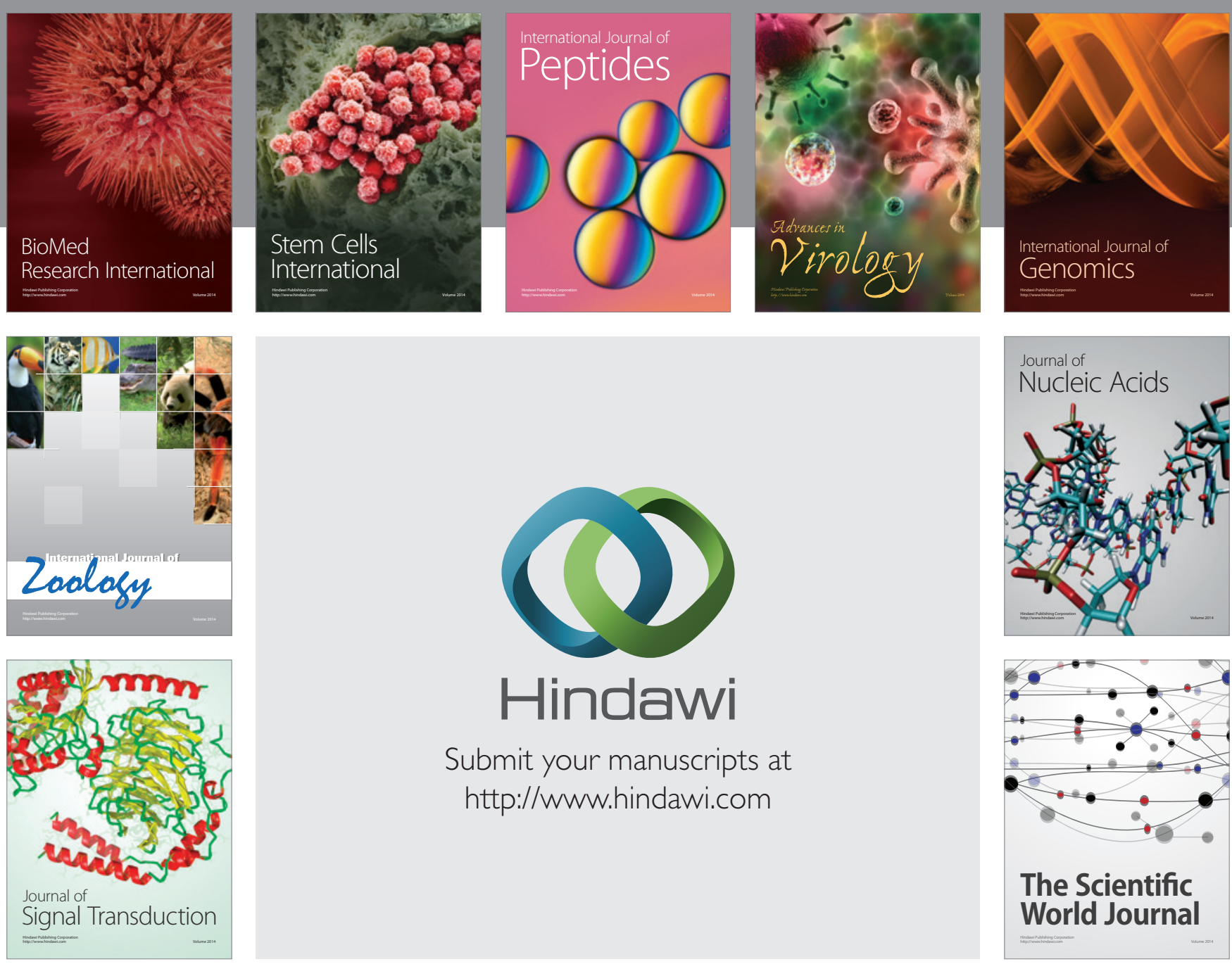

Submit your manuscripts at

http://www.hindawi.com
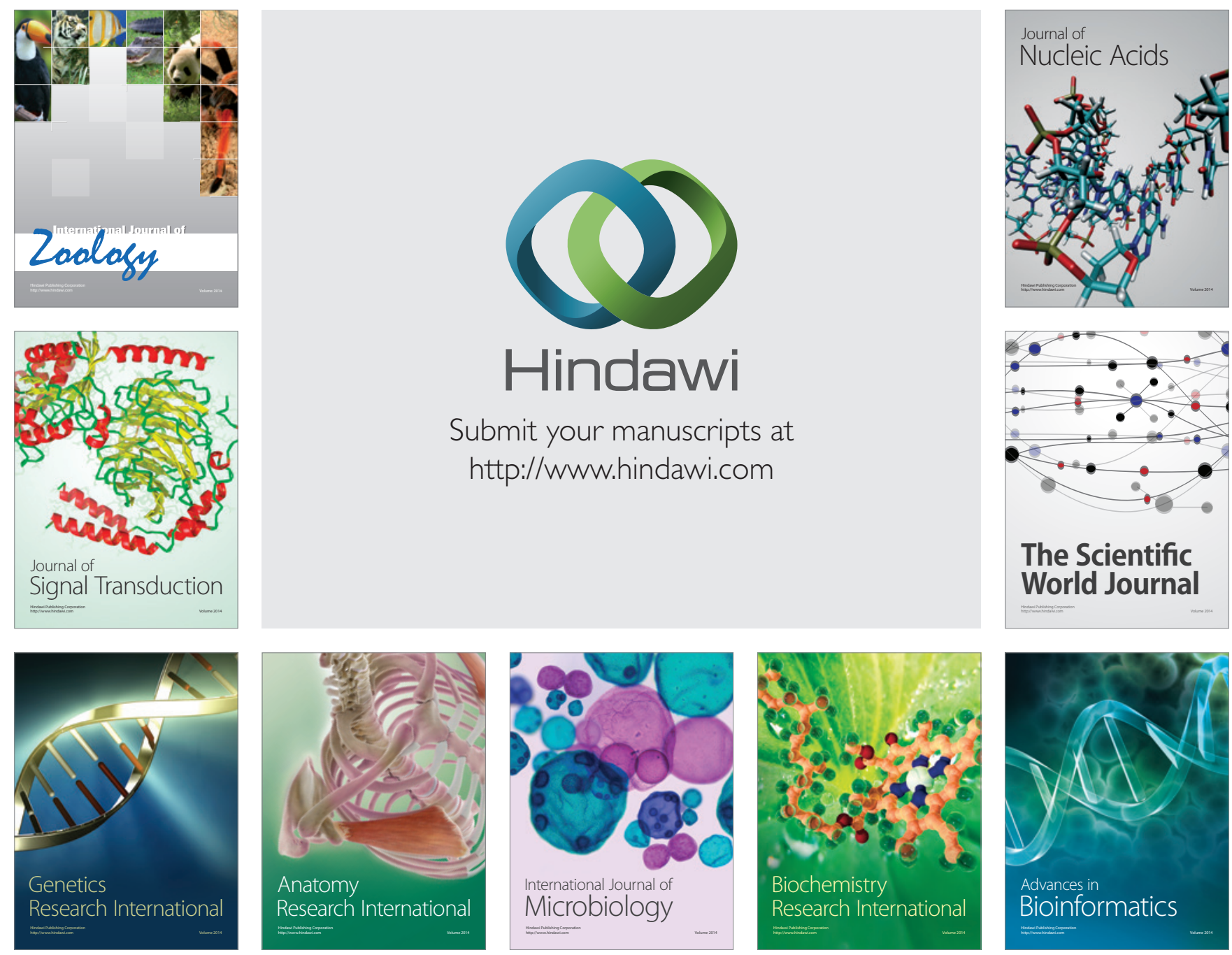

The Scientific World Journal
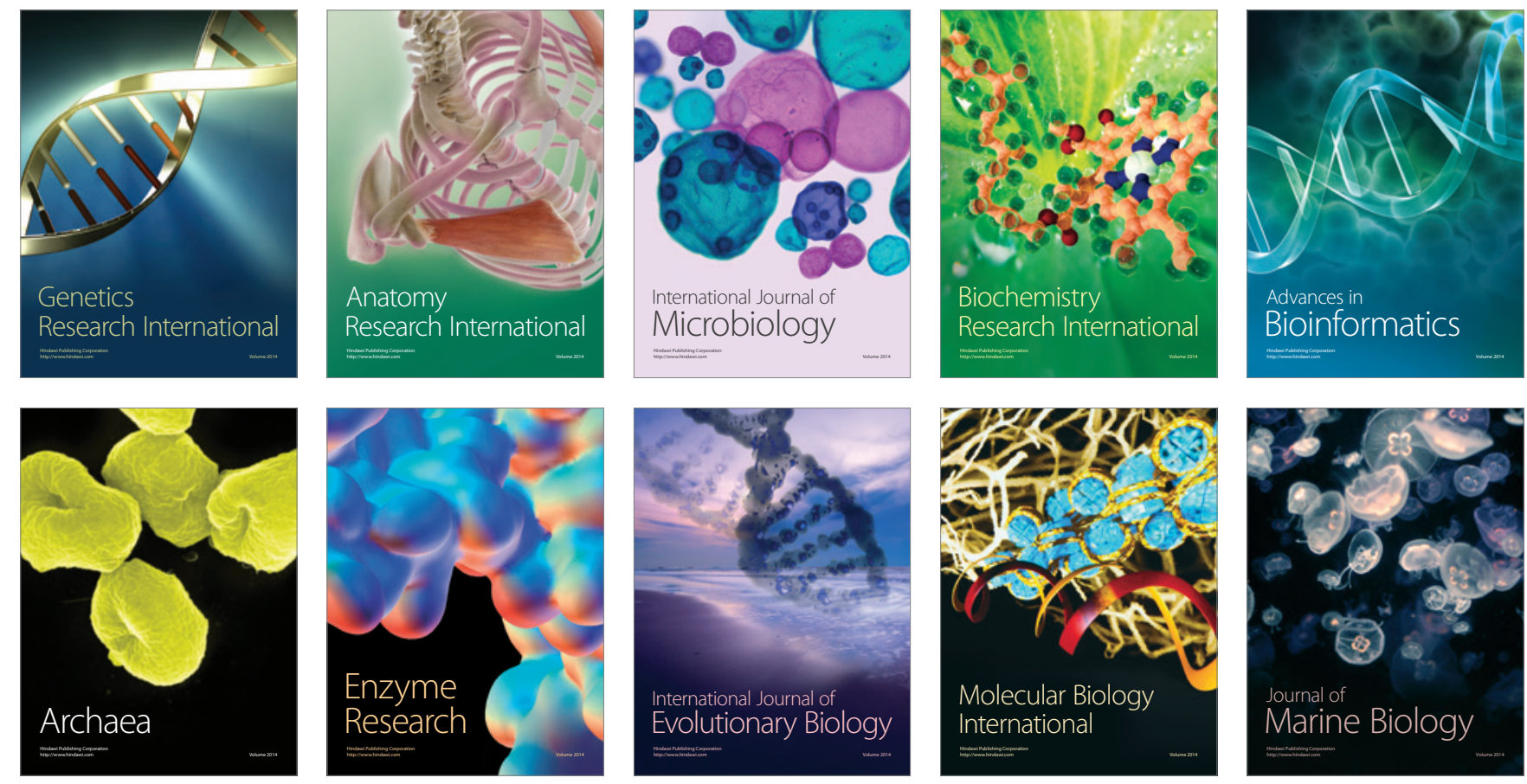